Article

\title{
Preparation and Characterization of $\mathrm{TiB}_{2}$-(Supra-Nano-Dual-Phase) High-Entropy Alloy Cermet by Spark Plasma Sintering
}

\author{
Shulei Zhang, Yuchen Sun, Boren Ke, Yulin Li, Wei Ji *, Weimin Wang and Zhengyi Fu \\ State Key Laboratory of Advanced Technology for Materials Synthesis and Processing, \\ Wuhan University of Technology, Wuhan 430070, China; zhangshulei@whut.edu.cn (S.Z.); \\ 15370786151231@whut.edu.cn (Y.S.); ke.@whut.edu.cn (B.K.); 1422915370@whut.edu.cn (Y.L.); \\ shswmwang@whut.edu.cn (W.W.); zyfu@whut.edu.cn (Z.F.) \\ * Correspondence: jiwei@whut.edu.cn; Tel.: +86-027-8786-5484
}

Received: 29 November 2017; Accepted: 9 January 2018; Published: 17 January 2018

\begin{abstract}
This paper introduces the preparation method and characterization results of $\mathrm{TiB}_{2}$ ceramics with CoCrFeNiAl high-entropy alloy (HEA) as a sintering aid by Spark Plasma Sintering (SPS). Good wettability between HEA and $\mathrm{TiB}_{2}$ was proved by the sessile drop method, indicating promising prospects for this composite. The sintering results showed that the addition of HEA could dramatically promote the sinterability of $\mathrm{TiB}_{2}$. $\mathrm{TiB}_{2}-5 \mathrm{wt}$. \% HEA dense ceramics prepared at the optimal temperature of $1650{ }^{\circ} \mathrm{C}$ showed fine morphology without formation of brittle phases. The liquid phase in the ceramics was highly consistent with the so-called "supra-nano-dual-phase materials (SNDPM)", with near-ideal strength. This study represents the first time that a ceramic-SNDPM composite has been fabricated since the invention of such structures.
\end{abstract}

Keywords: titanium diboride; high-entropy alloy; cermet; supra-nano-dual-phase

\section{Introduction}

As an advanced ceramic material, titanium diboride $\left(\mathrm{TiB}_{2}\right)$ has been widely applied in many fields, including cutting tools, high-temperature structural components, aluminum evaporation boats, conductive coatings, and armors in the military [1,2] due to its outstanding properties, which include its high melting point $\left(3225^{\circ} \mathrm{C}\right)$, hardness $(25-35 \mathrm{GPa})$, modulus (560 GPa), excellent wear resistance, high chemical stability, and good electrical and thermal conductivity [3,4]. However, because of the oxygen-rich layer $\left(\mathrm{TiO}_{2}\right.$ and $\left.\mathrm{B}_{2} \mathrm{O}_{3}\right)$, strong covalent bonding, and low self-diffusion coefficient, it is difficult to sinter $\mathrm{TiB}_{2}$ to full density [5,6], even with the assistance of pressure. In order to solve this problem, many methods have been explored. The most common method is to add some nonmetallic or metallic additives. $\mathrm{AlN}, \mathrm{TiN}, \mathrm{Si}_{3} \mathrm{~N}_{4}, \mathrm{TiSi}_{2}, \mathrm{MoSi}_{2}$, etc. are generally used as nonmetallic additives [7-10]. However, their effect on lowering the sintering temperature is not obvious. Some transition metallic elements, such as nickel, iron, and titanium have been tested as binders [11-14]. Compared with AlN et al., metals have better wettability with $\mathrm{TiB}_{2}$. It has been verified by experiments that these metals can dramatically decrease the sintering temperature when sintered with $\mathrm{TiB}_{2}$ [15]. However, the shortcoming of these metals is also obvious. Secondary borides like $M_{2} B$ and $M_{23} B_{6}$ produced during the sintering process greatly embrittle these products. As a result, it is necessary to search for new sintering additives for $\mathrm{TiB}_{2}$.

The high-entropy alloys (HEAs) designed by Yeh et al. are a new type of material that has been widely discussed in recent years [16]. The alloy contains at least five metallic elements in an equimolar or a near-equimolar ratio from 5 to 35 at. \% and the difference of atom radius among all the elements is supposed to be less than $15 \%$. Lattice distortion and sluggish cooperation co-exist in HEA, which 
are features of solid-solutions and amorphous phases, respectively; for this reason, HEAs with high mixing entropy of multiple-principal elements cannot be treated as traditional intermetallics. Different metallic element compositions lead to different properties. With proper composition design, the HEA is able to exhibit high hardness and excellent ductility, as well as promising resistances to wear, oxidation and corrosion [6,17]. HEA is an ideal material to act as a new sintering additive [18,19]. Mechanical alloying (MA) is an effective method for synthesizing HEA powder (CoCrFeNiAl, a very classical HEA system) with fine particle size and good chemical uniformity [20]. Therefore, HEA may be used as a sintering additive in ceramics.

In this study, we firstly gained equiatomic CoCrFeNiAl HEA powder by MA. Then, a sessile drop method was used to measure the wettability between as-milled HEA and $\mathrm{TiB}_{2}$ ceramic. Finally, $\mathrm{TiB}_{2}-\mathrm{HEA}$ ceramics were sintered at different temperatures via spark plasma sintering (SPS). In addition, the microstructures and mechanical properties of the bulks were investigated.

\section{Materials and Methods}

\subsection{Powder Preparation}

Commercially available titanium diboride powder (purity, 98\%; 3 $\mu \mathrm{m}$; Hubei Duobo New Ceramic Materials Co., Ltd., Wuhan, China) was used as the raw ceramic. The metal powders supplied by Sinopharm Chemical Reagent Co., Ltd. (Shanghai, China) included cobalt (purity, 99.5\%), chromium (purity, 99\%), iron (purity, 98\%), nickel (purity, 99.9\%), and aluminum (purity, 99.5\%). The powders were granulated by a 325-mesh sieve.

To mix and mill the metal powders, a high-performance stainless steel vial and stainless steel balls were used as milling agent. The weight ratio of the powders (Co., $\mathrm{Cr}, \mathrm{Fe}, \mathrm{Ni}$, and $\mathrm{Al}$ ) to the stainless steel balls was 15:1. The vials were filled with $\mathrm{N}$-heptane to avoid metal oxidation and cold welding. The vials were put in a planetary ball-miller (QM-BP, Nanjing Nanda Instrument Plant, Nanjing, China) for a total milling of $60 \mathrm{~h}$ at a speed of $250 \mathrm{rpm}$ in argon atmosphere.

After obtaining the CoCrFeNiAl HEA powders, 95 wt. \% $\mathrm{TiB}_{2}$ and 5 wt. \% HEA were mixed with agate balls in polyethylene jars loaded with ethyl alcohol as the medium. The jars were put on a wet ball miller (GMJ /B, Xianyangjinhong General Machinery Co., Ltd., Xianyang, China). After milling for $24 \mathrm{~h}$, the slurry was dried in a rotary evaporator at $65^{\circ} \mathrm{C}$ and the obtained powder was subsequently granulated with a 200-mesh sieve.

\subsection{Wettability Analysis}

High-temperature microscopy (EM-201, Leitz, Stuttgart, Germany) was used to observe the contact angle between $\mathrm{TiB}_{2}$ and $\mathrm{CoCrFeNiAl}$ HEA substrate by sessile drop method [21]. The surface of the $\mathrm{TiB}_{2}$ substrate was polished, and then sectioned into a wafer with a diameter of $20 \mathrm{~mm}$. The HEA powders were consolidated into the shape of cylinder and positioned in the center of the TiB2 substrate. When the temperature rose from room temperature to $1420{ }^{\circ} \mathrm{C}$ (higher than the melting point of the alloy [19]) in the argon atmosphere, the alloy was melted, and the contact angle could be observed.

\subsection{Sintering and Characterization}

The mixed powders were put in a graphite die with an inner diameter of $20 \mathrm{~mm}$ and sintered by SPS (Dr. Sinter-3.20MK II, Sumitomo, Osaka, Japan) at various sintering temperatures $\left(1500{ }^{\circ} \mathrm{C}\right.$, $1550{ }^{\circ} \mathrm{C}, 1600{ }^{\circ} \mathrm{C}, 1650{ }^{\circ} \mathrm{C}$ and $1700{ }^{\circ} \mathrm{C}$ ). The other conditions remained the same: a heating rate of $100{ }^{\circ} \mathrm{C} / \mathrm{min}$, an axial pressure of $30 \mathrm{MPa}, 5 \mathrm{~min}$ soaking in vacuum, and free cooling to room temperature after stopping the heating current.

An X-ray diffractometer (XRD, RigakuUltima III, Tokyo, Japan) was used to observe the crystal structure of the as-preserved specimen with $\mathrm{Cu} \mathrm{K} \alpha$ radiation, the scanning angle from $2 \theta=10^{\circ}$ to $2 \theta=90^{\circ}$, and a scanning rate of $4^{\circ} / \mathrm{min}$. Scanning electron microscopy (SEM, Hitachi 3400, Tokyo, Japan) was used to characterize the fracture surfaces of the samples. After ion milling, a thin foil of the 
sintered body was observed by transmission electron microscope (TEM, JEOL JEM-2010HT, Tokyo, Japan) equipped with energy-dispersive X-ray spectroscope (EDS, EDAX, Mahwah, NJ, USA) and selected area electron diffraction (SAED). A high-resolution transmission electron microscope (HRTEM, JEOL JEM-2010FEF, Tokyo, Japan) was utilized to obtain more detailed images of the microstructure. The Archimedes' drainage method was used to determine the density of the samples.

\subsection{Mechanical Properties}

The Vickers hardness was tested with via a Vickers hardness tester (Wolpert-430SV, Wolpert Wilson Instruments, Aachen, Germany) under a load of $5 \mathrm{~kg}$ for $15 \mathrm{~s}$. The flexural strength was obtained by three-point bending tests on bars $(2 \mathrm{~mm} \times 3 \mathrm{~mm} \times 17 \mathrm{~mm})$ in a ceramic test system (MTS 810, MTS Systems Corporation, Eden Prairie, MN, USA) with a span of $15 \mathrm{~mm}$ at a crosshead speed of $0.05 \mathrm{~mm} / \mathrm{min}$. Before mechanical testing, the specimens cut from the sintered bulk were polished down to $0.25 \mu \mathrm{m}$ by diamond suspension and the edges were chamfered in order to eliminate the negative effects of stress concentration. The reported values of all the mechanical properties are the average of 10 measurements.

\section{Results and Discussion}

Figure 1 shows the XRD patterns of the as-milled powder obtained after various milling times. The XRD patterns of all alloying elements can be observed. After grinding for $6 \mathrm{~h}$, the number of the diffraction peaks was unchanged. After grinding for $18 \mathrm{~h}$, peak broadening occurred and some peaks disappeared. From the XRD patterns, the three most intense peaks can be attributed to the BCC structure ((1 110$\left.),\left(\begin{array}{lll}2 & 0 & 0\end{array}\right),\left(\begin{array}{lll}2 & 1 & 1\end{array}\right)\right)$. The BCC phase of CoCrFeNiAl HEA indicated that a simple solid solution was successfully fabricated after milling for $30 \mathrm{~h}$. Further increasing the time above $18 \mathrm{~h}$ did not yield any significant difference.

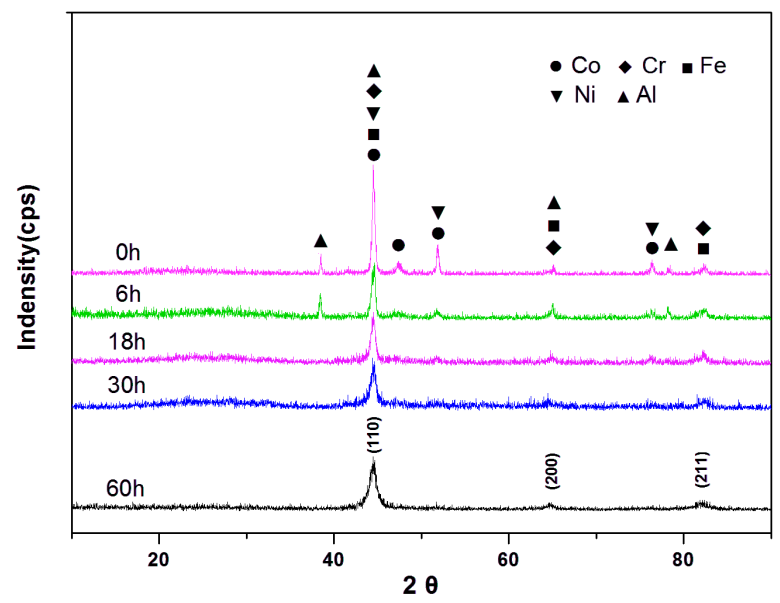

Figure 1. XRD patterns of CoCrFeNiAl HEA during $60 \mathrm{~h}$ milling.

Figure 2 shows the results of sessile drop experiments. The contact angles under different temperatures (from $25^{\circ} \mathrm{C}$ to $1403{ }^{\circ} \mathrm{C}$ ) between HEA and the $\mathrm{TiB}_{2}$ substrate can be seen from these images. Figure $2 \mathrm{~b}$ reveals that there is no obvious change for either HEA or the ceramic substrate, other than some expansion when the temperature reached $1200^{\circ} \mathrm{C}$. When the temperature rises to $1390{ }^{\circ} \mathrm{C}$, the HEA cylinder starts to melt, and the contact angle between the HEA cylinder and the ceramic substrate can be observed. As shown in Figure $2 \mathrm{c}-\mathrm{e}$, when the temperature exceeds $1390^{\circ} \mathrm{C}$, the HEA melts fast, and the contact angle becomes much smaller. Figure $2 \mathrm{f}$ indicates that at the end of this process, the molten HEA almost completely spreads onto the substrate. According to the available literature, this result indicates excellent wetting properties between $\mathrm{TiB}_{2}$ ceramic and 
molten CoCrFeNiAl HEA [22]. Wettability is one of the most important aspects for the fabrication of metal-ceramic composites. Good wettability will promote the sinterability of $\mathrm{TiB}_{2}$ ceramics.
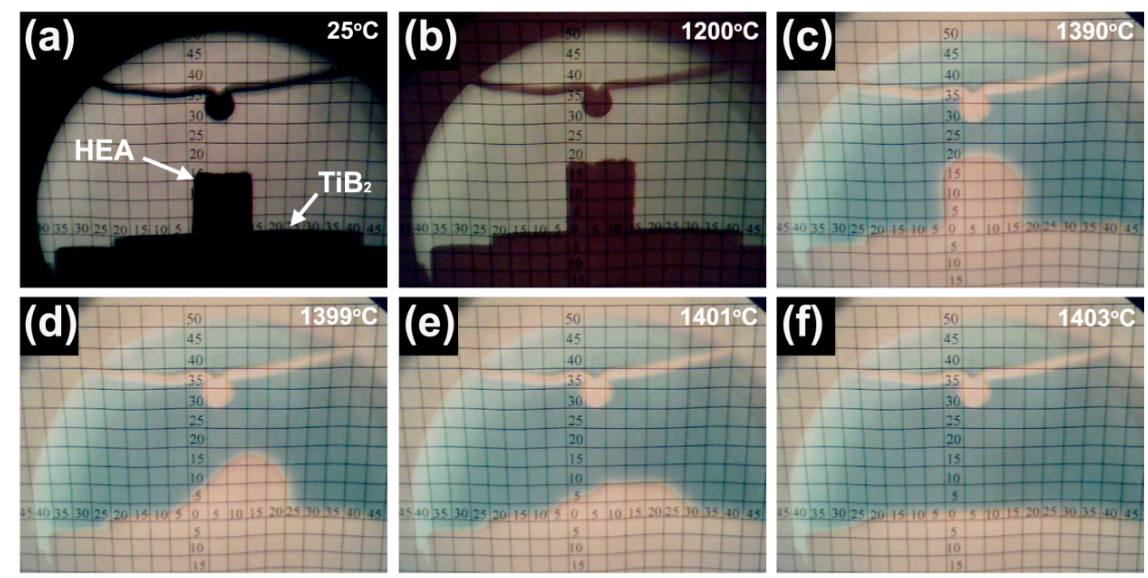

Figure 2. Wetting ability test between $\mathrm{CoCrFeNiAl}$ high-entropy alloy and $\mathrm{TiB}_{2}$ substrate at different temperatures: (a) $25{ }^{\circ} \mathrm{C}$; (b) $1200{ }^{\circ} \mathrm{C}$; (c) $1390{ }^{\circ} \mathrm{C}$; (d) $1399{ }^{\circ} \mathrm{C}$; (e) $1401{ }^{\circ} \mathrm{C}$ and (f) $1403{ }^{\circ} \mathrm{C}$.

The XRD patterns of the $\mathrm{TiB}_{2}-5$ wt. \% CoCrFeNiAl mixture and the as-sintered bodies are shown in Figure 3. Only a $\mathrm{TiB}_{2}$ phase is observed in the mixed powder, and no obvious HEA peak can be observed. The invisibility of the HEA peaks can be ascribed to: Firstly, the MA process causes the low crystallinity of HEA. MA leads to some lattice distortions such as random solid solution, nanoparticles, and the amorphous phase [23]. In addition, HEA only accounts for $5 \%$ of the total powders, and cannot be detected. Secondly, both $\mathrm{TiB}_{2}$ and the as-milled CoCrFeNiAl HEA have peaks at a $2 \theta$ of about $44.5^{\circ}$. Therefore, it is difficult to distinguish the HEA peaks from the patterns. As a consequence, XRD, which is used to test the crystalline phase, cannot identify X-ray diffraction peaks whose intensity is not strong enough. Whether the HEA exists or not will be verified in the following discussion. As for the small metallic oxides (MO) phase in the XRD at $1700^{\circ} \mathrm{C}$, the elements with relatively low alloying degrees can exsolute from the HEA and react with the impurities from raw $\mathrm{TiB}_{2}$ powders to form some metallic oxides. This side reaction is a favorable way of eliminating impurities in raw $\mathrm{TiB}_{2}$ powder, thus promoting the sinterability of ceramics. Additionally, the peaks of brittle secondary borides $\left(M_{2} B\right.$, $\mathrm{M}_{23} \mathrm{~B}_{6}$ ) cannot be observed in the as-sintered ceramics.

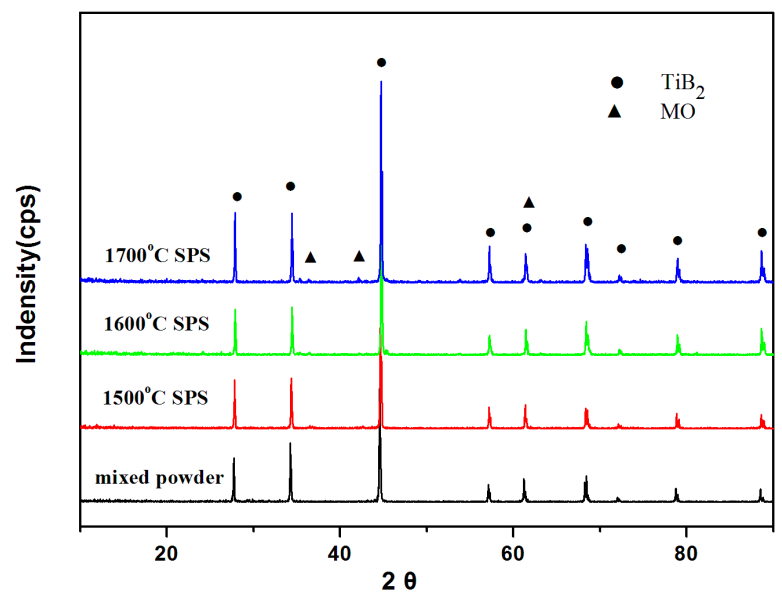

Figure 3. XRD patterns of the mixed powder and $\mathrm{TiB}_{2}-5 \mathrm{wt}$. \% HEA ceramics sintered at $1500{ }^{\circ} \mathrm{C}$, $1600{ }^{\circ} \mathrm{C}$, and $1700{ }^{\circ} \mathrm{C}$ by SPS. 
Figure 4a shows SEM micrographs of the pure $\mathrm{TiB}_{2}$ ceramic sintered at $1700{ }^{\circ} \mathrm{C}$ without a sintering aid. Many open pores exist in the body, and the density is low. Therefore, pure $\mathrm{TiB}_{2}$ ceramic cannot be easily sintered to high density at temperatures below $1700{ }^{\circ} \mathrm{C}$. SEM micrographs of $\mathrm{TiB}_{2}$ sintered with 5 wt. \% CoCrFeNiAl HEA obtained at different temperatures are shown in Figure $4 \mathrm{~b}-\mathrm{f}$. The comparison results with/without addition of HEA indicate that the addition of HEA can dramatically promote the sinterability of $\mathrm{TiB}_{2}$. The relative density of the as-sintered samples with HEA increases with the temperature increase. The few pores observed in Figure $4 \mathrm{~b}$ indicate that high density cannot be achieved at low temperature $\left(1500{ }^{\circ} \mathrm{C}\right)$. The densification of $\mathrm{TiB}_{2}$ is remarkably enhanced with the temperature rise, as shown in Figure $4 \mathrm{c}-\mathrm{f}$. However, when the temperature reaches $1700{ }^{\circ} \mathrm{C}$, much coarser grains appear. Therefore, $1650^{\circ} \mathrm{C}$ is the optimal temperature for obtaining composites with both high density and small grain size, which are the requirements for ceramic materials with good mechanical properties.
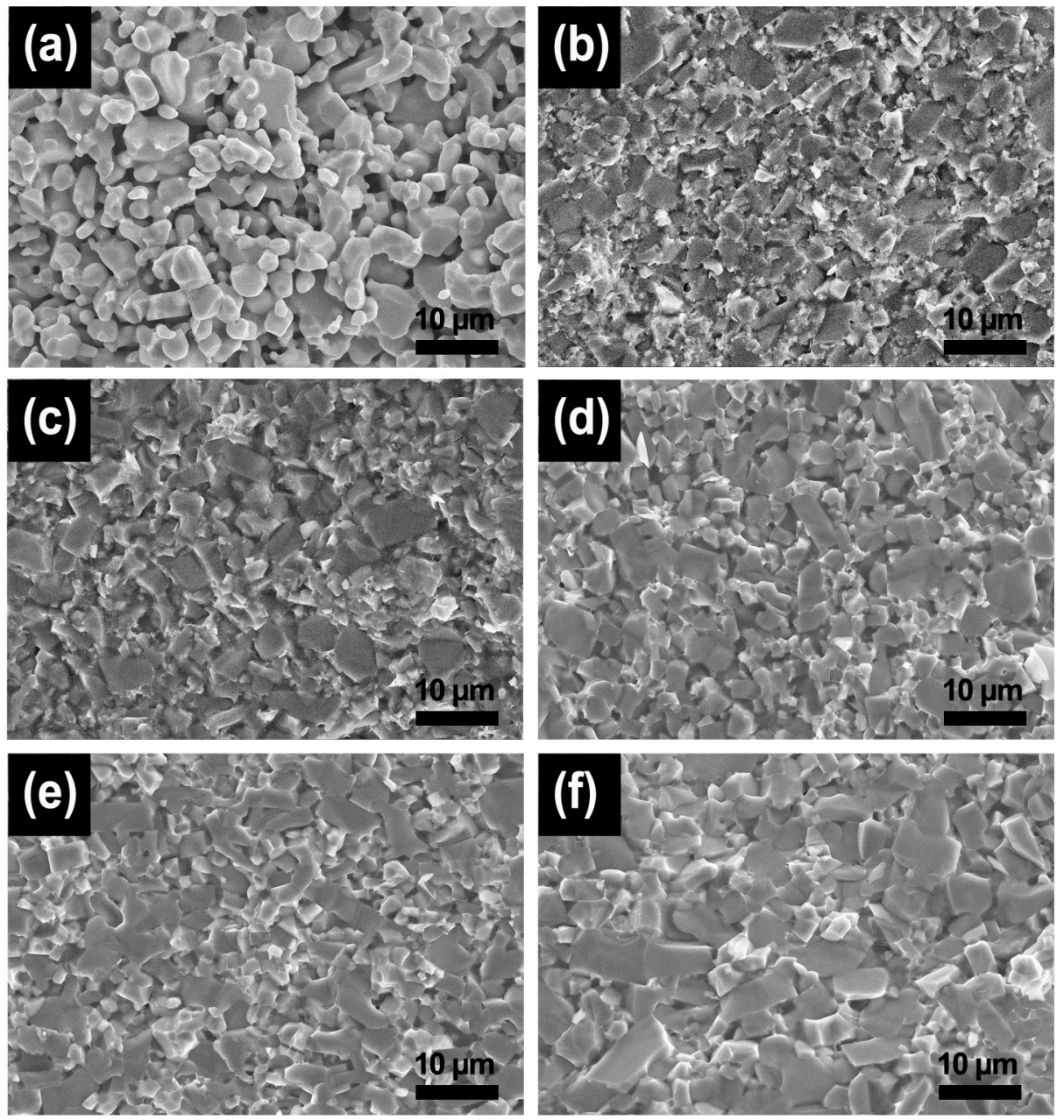

Figure 4. SEM images of (a) pure $\mathrm{TiB}_{2}$ sintered at $170{ }^{\circ} \mathrm{C}$ and $(\mathbf{b}-\mathbf{f}) \mathrm{TiB}_{2}$ with 5 wt. $\% \mathrm{CoCrFeNiAl}$ high-entropy alloy addition under different temperatures: (b) $1500{ }^{\circ} \mathrm{C}$; (c) $1550{ }^{\circ} \mathrm{C}$; (d) $1600{ }^{\circ} \mathrm{C}$; (e) $1650{ }^{\circ} \mathrm{C}$; (f) $1700{ }^{\circ} \mathrm{C}$.

High-magnification secondary electron (SE) and backscattered electron (BSE) SEM images of the fracture surface of $\mathrm{TiB}_{2}-5 \mathrm{wt}$. \% CoCrFeNiAl ceramics sintered at $1650{ }^{\circ} \mathrm{C}$ are shown in Figure 5 . The good wettability between $\mathrm{TiB}_{2}$ and HEA can be certified by the morphology. The bright phase is situated between grain boundaries, and its shape depends on the profile of the adjacent $\mathrm{TiB}_{2}$ grains. This phase can be preliminarily identified as HEA, because the HEA alloy melts into liquid phases at high temperatures. Liquid phase with excellent fluidity can enhance the densification of ceramics. 

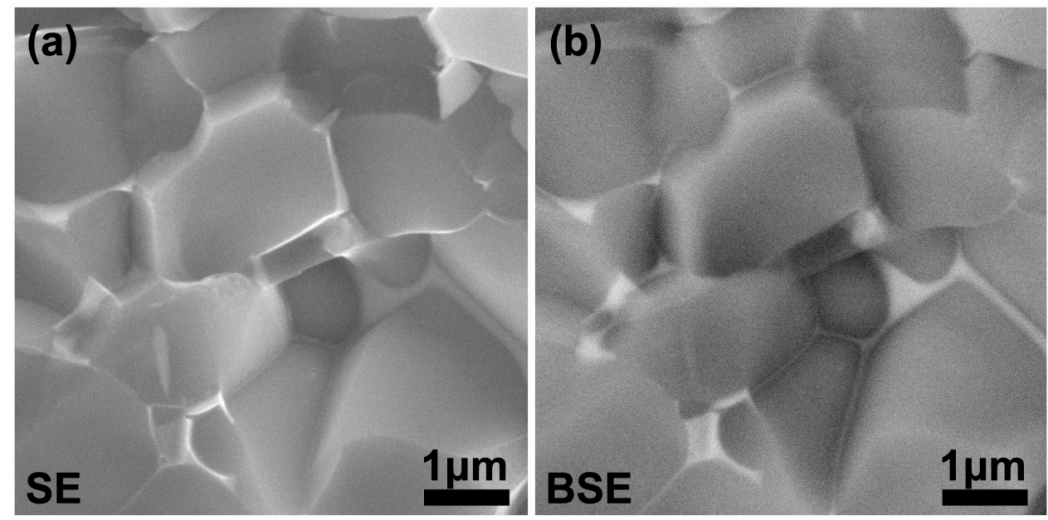

Figure 5. (a) SEM SE image and (b) the corresponding BSE image of the fracture surface of $\mathrm{TiB}_{2}-5 \mathrm{wt}$. \% $\mathrm{CoCrFeNiAl} \mathrm{composites} \mathrm{sintered} \mathrm{at} 1650{ }^{\circ} \mathrm{C}$.

Figure 6a shows a TEM image of $\mathrm{TiB}_{2}$-HEA composites sintered at $1650{ }^{\circ} \mathrm{C}$. The corresponding SAED patterns of the sample in Figure $6 \mathrm{~b}$ reveal that the light area is $\mathrm{TiB}_{2}$ grain. The EDS result in Figure $6 \mathrm{c}$ indicates that the liquid phase surrounded by $\mathrm{TiB}_{2}$ is HEA, because the elements in this phase only include $\mathrm{Cr}, \mathrm{Ni}, \mathrm{Co}$., $\mathrm{Fe}$, and $\mathrm{Al}$, which are the original components in the HEA.

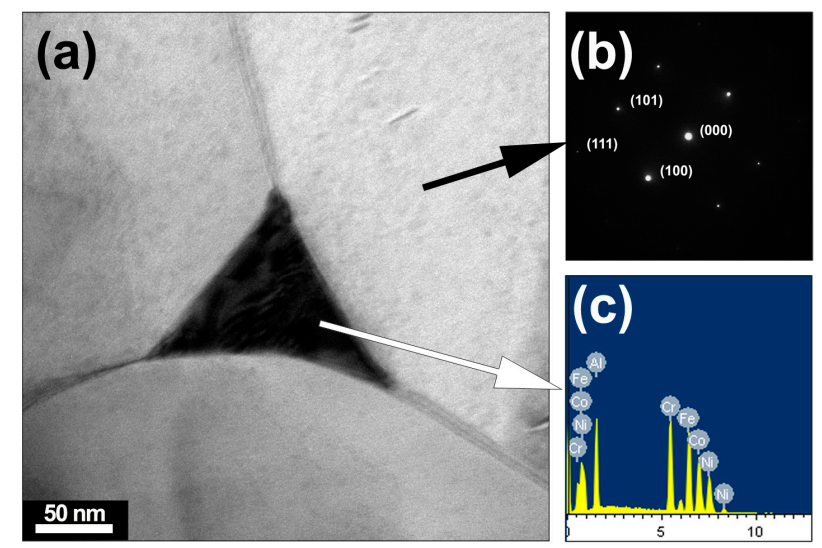

Figure 6. (a) TEM images of a bright place selected from the $\mathrm{TiB}_{2}-5 \mathrm{wt}$. \% HEA composites sintered at $1650{ }^{\circ} \mathrm{C}$; (b) corresponding SAED of grain phase; (c) corresponding EDS patterns of liquid phase.

According to the TEM images of the boundary between ceramic and liquid phase in Figure 7a, the lower part is $\mathrm{TiB}_{2}$, as can be recognized from the complete lattice fringe, whereas the upper part is HEA. The inconspicuous grain boundary between HEA and the ceramics reveals a tight boundary structure, which is favorable to excellent mechanical properties.

HEA phase contains amorphous phases, ordered or disordered solid-solution phases, and nano-sized precipitations. There are two main reasons for the presence of amorphous phases. The first is related to the core effects of HEAs: high entropy effect, severe lattice distortion effect, and sluggish diffusion effect [24]. The high entropy of $1.61 \mathrm{R}\left(\mathrm{R}=8.31 \mathrm{~J} \cdot \mathrm{mol}^{-1} \cdot \mathrm{K}^{-1}\right.$, the gas constant $)$ for CoCrFeNiAl HEA makes it possible to reduce the rate of atomic diffusion and inhibit the crystallization. Secondly, mechanical alloying is in favorable to amorphization. The amorphous phase would be produced during mechanical alloying. According to previous results [24], HEAs containing multiple-principal elements possess sluggish diffusion. The atoms are very hard to replace with others, and the diffusion is inhibited between regions. The diffusion of phase separation is also slow over a long range. All the above factors slow down crystal nucleation and growth, and promote nano-precipitation growth. 
For the further confirmation of phase composition, the liquid phase area was observed by HRTEM, as shown in Figure 7b,c. Nanoparticles are conspicuous in the liquid phase of HEA, with a size of 5-10 nm embedded in the amorphous phase. Fast Fourier Transform (FFT) image indicates that these nano-precipitates are simple face-centered cubic (FCC) structures [12]. It is known that the structure of CoCrFeNiAl HEA is body-centered cubic (BCC) following synthesis with the MA process, but the BCC phase prepared in the non-equilibrium process is metastable, and the CoCrFeNiAl HEA will be converted into an FCC structure beyond $100{ }^{\circ} \mathrm{C}$, according to our previous research $[20,25]$. Moreover, the particle size is almost the same as that of mechanically alloyed HEAs. Based on the above discussion, the phase composition and distribution are clear. Additionally, the atomic packing rate of FCC structure is $74 \%$, whereas that of BCC structures is only $68 \%$. Dense packing would make the alloy melt with high viscosity and low atomic mobility, which would greatly reduce the nucleation rate and growth velocity, and facilitate amorphization [26,27].
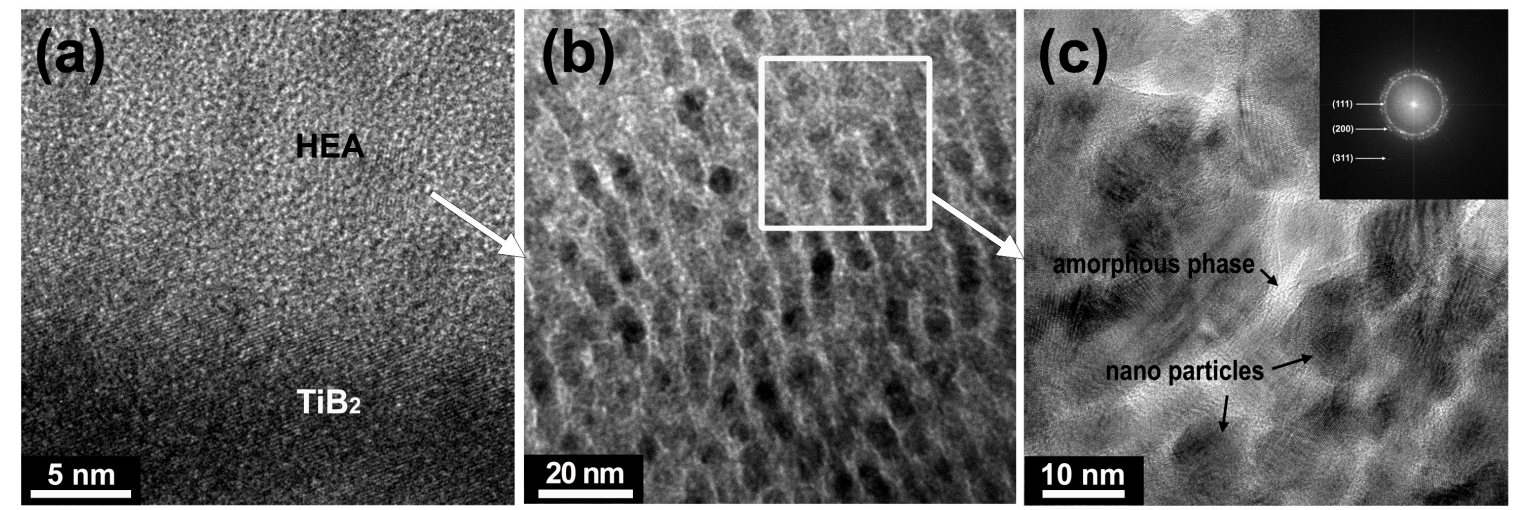

Figure 7. (a) HRTEM images of the interface between $\mathrm{TiB}_{2}$ and $\mathrm{HEA}$ for the $\mathrm{TiB}_{2}-5$ wt. $\% \mathrm{CoCrFeNiAl}$ HEA composites sintered at $1650{ }^{\circ} \mathrm{C}$; (b) Supra-nano-dual-phase structure in the liquid phase and (c) HRTEM image of the nanostructured CoCrFeNiAl HEA within amorphous shells. Inset, a fast Fourier transform image of HEA liquid phase.

The combined nanocrystalline-amorphous structure (the size of each phase is less than $10 \mathrm{~nm}$ ) exhibits near-ideal strength at room temperature [28]. The so-called "supra-nano-dual-phase structure (SNDP)" agrees well with that in the liquid phase in the study. This is the first time a ceramic-SNDP composite has been obtained, and its structure also indicates excellent properties for the $\mathrm{TiB}_{2}$-HEA cermet.

Figure 8 shows some physical and mechanical properties of $\mathrm{TiB}_{2}-5$ wt. \% HEA ceramics obtained at different sintering temperatures. It is obvious that all the properties increase with the temperature going up from $1500{ }^{\circ} \mathrm{C}$ to $1650{ }^{\circ} \mathrm{C}$. The peak values appear at $1650{ }^{\circ} \mathrm{C}$ with a relative density of $99.62 \pm 0.12 \%$, a flexural strength of $820 \pm 9 \mathrm{MPa}$ and a Vickers hardness of $2386 \pm 18$ HV5. However, when the temperature continues to rise, a slight decreasing trend can be observed in the line chart. The increase in densities and the enhancement of bond strength between $\mathrm{TiB}_{2}$ and $\mathrm{HEA}$ will raise the hardness and strength of the composites. The grain growth caused by high temperatures prevents the further improvement of the mechanical properties.

Barandika reported that monolithic $\mathrm{TiB}_{2}$ sintered at $1800{ }^{\circ} \mathrm{C}$ and $30 \mathrm{MPa}$ showed a relative density of $96.1 \%$, a flexural strength of $367.1 \mathrm{MPa}$, and a Vickers hardness of $24 \mathrm{GPa}$ [11]. Kang and co-workers obtained $95 \%$ densified $\mathrm{TiB}_{2}$ with Fe addition at a temperature of $2000{ }^{\circ} \mathrm{C}$. The specimen shows a flexural strength of $400 \mathrm{MPa}$ [16]; Park et al. used $\mathrm{Si}_{3} \mathrm{~N}_{4}$ as an additive. The experiment was carried out by hot press sintering at $1800{ }^{\circ} \mathrm{C}$ with $30 \mathrm{MPa}$. The samples provided $97.5 \%$ relative density, $500 \mathrm{MPa}$ of flexural strength and $22 \mathrm{GPa}$ of Vickers hardness [10]. To achieve a high relative density (>97\%) for monolithic $\mathrm{TiB}_{2}$ ceramics, a high SPS temperature $\left(>1800{ }^{\circ} \mathrm{C}\right)$ is required [15]. However, in this study, $1650{ }^{\circ} \mathrm{C}$ was sufficient to fabricate highly dense ceramics, thus effectively saving energy. 
Moreover, compared with other additives, HEA is good for achieving an excellent combination of various mechanical properties, including 99.62\% relative density, $820 \mathrm{MPa}$ flexural strength, and 23.89 GPa Vickers hardness. The attractive properties can be attributed to (1) the good wetting ability, which has been proved in wetting ability testing to be conducive to bonding between different phases, and to further enhance mechanical properties; (2) there being no secondary brittle borides $\left(\mathrm{M}_{2} \mathrm{~B}\right.$ or $\mathrm{M}_{23} \mathrm{~B}_{6}$ ) are produced during sintering; and (3) the excellent mechanical properties of $\mathrm{CoCrFeNiAl}$ HEA with a supra-nano-dual-phase structure [29].

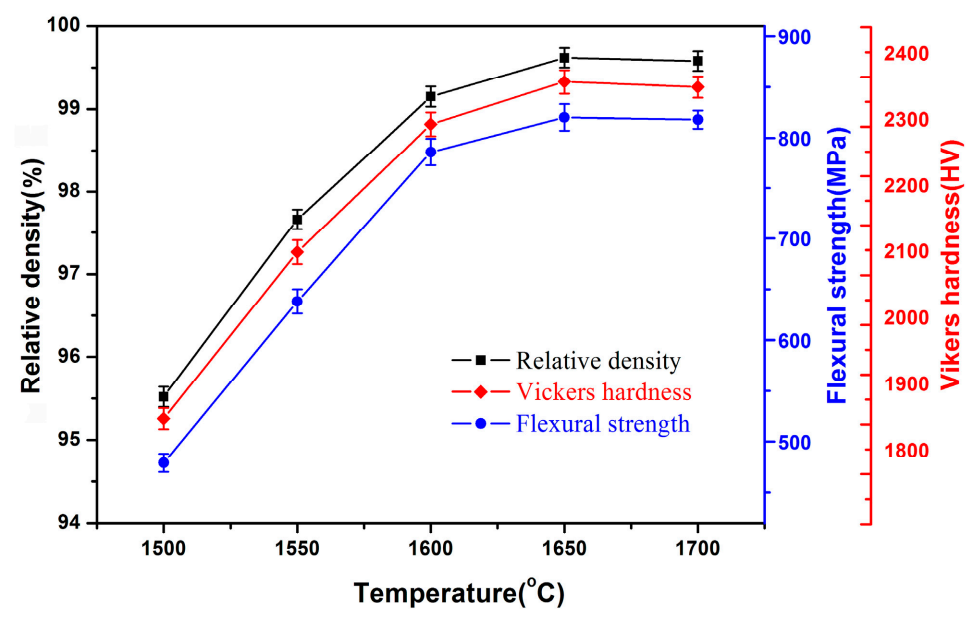

Figure 8. Line chart of mechanical properties of $\mathrm{TiB}_{2}-5$ wt. $\%$ CoCrFeNiAl HEA composites sintered at different temperatures from $1500{ }^{\circ} \mathrm{C}$ to $1700^{\circ} \mathrm{C}$.

\section{Conclusions}

This work mainly focuses on the preparation method and characterization of $\mathrm{TiB}_{2}-\mathrm{CoCrFeNiAl}$ high-entropy alloy by spark plasma sintering at different temperatures from $1500{ }^{\circ} \mathrm{C}$ to $1700{ }^{\circ} \mathrm{C}$. The conclusions are drawn as follows.

Equiatomic CoCrFeNiAl high-entropy alloy with BCC structure was fabricated by mechanical alloying after $30 \mathrm{~h}$ milling.

The HEA spreads on the ceramic substrate completely when the temperature is higher than $1390{ }^{\circ} \mathrm{C}$. The results show excellent wettability between the two phases, which leads to excellent physical compatibility.

The as-sintered $\mathrm{TiB}_{2}$-HEA bodies do not contain brittle phases, which are expected to degrade the mechanical properties.

TEM images reveal high density and tight grain boundary between $\mathrm{TiB}_{2}$ ceramic and HEA liquid phase, which are essential requirements for excellent mechanical properties.

The liquid phase in the ceramics agrees well with the so-called "supra-nano-dual-phase materials (SNDPM)" with near-ideal strength.

The $\mathrm{TiB}_{2}$-HEA composites could be obtained at $1650{ }^{\circ} \mathrm{C}$, which is lower than that obtained in previous studies on $\mathrm{TiB}_{2}$-based ceramics. Meanwhile, the mechanical and physical properties with a relative density of $99.62 \pm 0.12 \%$, a flexural strength of $820 \pm 9 \mathrm{MPa}$ and a Vickers hardness of $2386 \pm 18$ HV5 are superior to previous results.

Acknowledgments: This work was financially supported by the National Natural Science Foundation of China (51521001, 51672197, 5167020705, and 51502220), the National Key Research and Development Plan of China (2017YF130310400), and the Self-determined and Innovative Research Funds of WHUT (2017II17XZ, 2017III03 and 20171049701006). The authors also thank Xuefeng Ruan from School of Power and Mechanical Engineering of Wuhan University for the help in Spark Plasma Sintering, Rong Jiang and Tingting Luo from Materials Analysis Center of Wuhan University of Technology for their help in assisting TEM analyses. 
Author Contributions: W.J. and S.Z. conceived and designed the experiments; Y.S. and Y.L. performed the experiments; W.J. and B.K. analyzed the data; W.J. and S.Z. wrote the paper; Z.F. and W.W. modified the paper.

Conflicts of Interest: The authors declare no conflict of interest.

\section{References}

1. Wen, G.; Li, S.; Zhang, B.; Guo, Z. Reaction synthesis of $\mathrm{TiB}_{2}-\mathrm{TiC}$ composites with enhanced toughness. Acta Mater. 2001, 49, 1463-1470. [CrossRef]

2. Gu, M.; Huang, C.; Zou, B.; Liu, B. Effect of (Ni, Mo) and TiN on the microstructure and mechanical properties of $\mathrm{TiB}_{2}$ ceramic tool materials. Mater. Sci. Eng. A 2006, 433, 39-44. [CrossRef]

3. Basu, B.; Raju, G.B.; Suri, A.K. Processing and properties of monolithic $\mathrm{TiB}_{2}$ based materials. Int. Mater. Rev. 2006, 51, 352-374. [CrossRef]

4. Vallauri, D.; Adrian, I.C.A.; Chrysanthou, A. TiC-TiB 2 composites: A review of phase relationships, processing and properties. J. Eur. Ceram. Soc. 2008, 28, 1697-1713. [CrossRef]

5. Raju, G.; Mukhopadhyay, A.; Biswas, K.; Basu, B. Densification and high-temperature mechanical properties of hot pressed $\mathrm{TiB}_{2}-(0-10$ wt.\%) MoSi 2 composites. Scr. Mater. 2009, 61, 674-677. [CrossRef]

6. Wang, W.; Fu, Z.; Wang, H.; Yuan, R. Influence of hot pressing sintering tempera-ture and time on microstructure and mechanical properties of $\mathrm{TiB}_{2}$ ceramics. J. Eur. Ceram. Soc. 2002, 22, 1045-1049. [CrossRef]

7. Li, L.; Kim, H.; Kang, E. Sintering and mechanical properties of titanium diboride with aluminum nitride as a sintering aid. J. Eur. Ceram. Soc. 2002, 22, 973-977. [CrossRef]

8. Park, J.; Koh, Y.; Kim, H.; Hwang, C.; Kang, E. Densification and mechanical properties of titanium diboride with silicon nitride as a sintering aid. J. Am. Ceram. Soc. 1999, 82, 3037-3042. [CrossRef]

9. Mukhopadhyay, A.; Raju, G.; Basu, B.; Suri, A. Correlation between phase evolution, mechanical properties and instrumented indentation response of $\mathrm{TiB}_{2}$-based ceramics. J. Eur. Ceram. Soc. 2009, 29, 505-516. [CrossRef]

10. Zheng, L.; Li, F.; Zhou, Y. Preparation, microstructure, and mechanical properties of $\mathrm{TiB}_{2}$ using $\mathrm{Ti}_{3} \mathrm{AlC}_{2}$ as a sintering aid. J. Am. Ceram. Soc. 2012, 95, 2028-2034. [CrossRef]

11. Barandika, M.; Sanchez, J.; Rojo, T.; Cortes, R.; Castro, F. Fe-Ni-Ti binder phases for TiB $_{2}$-based cermets: A thermodynamic approach. Scr. Mater. 1998, 39, 1395-1400. [CrossRef]

12. Einarsrud, M.; Hagen, E.; Pettersen, G.; Grande, T. Pressureless sintering of titanium diboride with nickel, nickel boride and iron additives. J. Am. Ceram. Soc. 1997, 8, 3013-3020. [CrossRef]

13. Zhang, Z.; Shen, X.; Wang, F.; Lee, S.; Fan, Q.; Cao, M. Low-temperature densification of $\mathrm{TiB}_{2}$ ceramic by the spark plasma sintering process with Ti as a sintering aid. Scr. Mater. 2012, 66, 167-170. [CrossRef]

14. Kang, E.; Jang, C.; Lee, C.; Kim, C.; Kim, D. Effect of iron and boron carbide onthe densification and mechanical properties of titanium diboride ceramics. J. Am. Ceram. Soc. 1989, 72, 1868-1872. [CrossRef]

15. Zhang, J.; Fu, Z.; Wang, W.; Wang, H.; Min, X. Wettability between TiB 2 ceramic and metals. Acta Metall. Sin. 1999, 12, 395-400.

16. Yeh, J.-W.; Chen, S.-K.; Lin, S.-J.; Gan, J.-Y.; Chin, T.-S.; Shun, T.-T.; Tsau, C.-H.; Chang, S.-Y. Nanostructured high-entropy alloys with multiple principal elements: Novel alloy design concepts and outcomes. Adv. Eng. Mater. 2004, 6, 299-303. [CrossRef]

17. Otto, F.; Yang, Y.; Bei, H.; George, E. Relative effects of enthalpy and entropy on the phase stability of equiatomic high-entropy alloys. Acta Mater. 2013, 61, 2628-2638. [CrossRef]

18. Zhu, G.; Liu, Y.; Ye, J. Fabrication and properties of $\operatorname{Ti}(\mathrm{C}, \mathrm{N})$-based cermets with multi-component AlCoCrFeNi high-entropy alloys binder. Mater. Lett. 2013, 113, 80-82. [CrossRef]

19. Fu, Z.; Koc, R. Processing and characterization of $\mathrm{TiB}_{2}-\mathrm{TiNiFeCrCoAl} \mathrm{high-entropy} \mathrm{alloy} \mathrm{composite.} \mathrm{J.} \mathrm{Am.}$ Ceram. Soc. 2017, 100, 2803-2813. [CrossRef]

20. Ji, W.; Fu, Z.; Wang, W.; Wang, H.; Zhang, J.; Wang, Y.; Zhang, F. Mechanical alloying synthesis and spark plasma sintering consolidation of CoCrFeNiAl high-entropy alloy. J. Alloys Compd. 2014, 589, 61-66. [CrossRef]

21. Zheng, X.; Shen, P.; Han, X.; Lin, Q.; Qiu, F.; Zhang, Y.; Jiang, Q. Wettability and reactivity between $\mathrm{B}_{4} \mathrm{C}$ and Molten $\mathrm{Zr}_{55} \mathrm{Cu}_{30} \mathrm{Al}_{10} \mathrm{Ni}_{5}$ metallic glass alloy. Mater. Chem. Phys. 2009, 117, 377-383. [CrossRef] 
22. Aizenshtein, M.; Froumin, N.; Frage, N. The nature of $\mathrm{TiB}_{2}$ wetting by $\mathrm{Cu}$ and Au. J. Mater. Eng. Perform 2012, 21, 655-659. [CrossRef]

23. Varalakshmi, S.; Kamaraj, M.; Murty, B. Synthesis and characterization of nanocrystalline AlFeTiCrZnCu high entropy solid solution by mechanical alloying. J. Alloys Compd. 2008, 460, 253-257. [CrossRef]

24. Zhang, X.; Zhang, Y.; Qiao, Y.; Chen, G. Novel microstructure and properties of multicomponent $\mathrm{CoCrCuFeNiTi}_{\mathrm{x}}$ alloys. Intermetallics 2007, 15, 357-362. [CrossRef]

25. Ji, W.; Wang, W.; Wang, H.; Zhang, J.; Wang, Y.; Zhang, F.; Fu, Z. Alloying behavior and novel properties of $\mathrm{CoCrFeNiMn}$ high-entropy alloy fabricated by mechanical alloying and spark plasma sintering. Intermetallics 2015, 56, 2-27. [CrossRef]

26. Li, Y.; Guo, Q.; Kalb, J.A.; Thompson, C.V. Matching glass-forming ability with the density of the amorphous phase. Science 2008, 322, 1816-1819. [CrossRef] [PubMed]

27. Li, R.; Pang, S.; Men, H.; Ma, C.; Zhang, T. Formation and mechanical propertie sof (Ce-La-Pr-Nd)-Co-Al bulk glassy alloys with superior glass-forming ability. Scr. Mater. 2006, 54, 1123-1126. [CrossRef]

28. Wu, G.; Chan, K.; Zhu, L.; Sun, L.; Lu, J. Dual-phase nanostructuring as a route to high-strength magnesium alloys. Nature 2017, 545, 80-83. [CrossRef] [PubMed]

29. Zhang, Y.; Zuo, T.T.; Tang, Z.; Gao, M.C.; Dahmen, K.A.; Liaw, P.K.; Lu, Z.P. Microstructures and properties of high-entropy alloys. Prog. Mater. Sci. 2014, 61,1-93. [CrossRef]

(c) 2018 by the authors. Licensee MDPI, Basel, Switzerland. This article is an open access article distributed under the terms and conditions of the Creative Commons Attribution (CC BY) license (http://creativecommons.org/licenses/by/4.0/). 